\title{
Sex differences in the activity wheel \\ as a function of fetal age at irradiation'
}

JOAN C. MARTIN,2,3 Duke Medical Center, Durham, N. C. 27706

Female offspring of gravid rats administered a single dose of $200 R$ of ionizing irradiation on Gestation Days 17, 19, or 21 remained significantly more active than similarly treated males. Both groups increased their activity over control levels with a lesser effect in evidence for 17 and 21 day males. Day 19 males were, unexpectedly, as active as the comparable female group.

The following experiment is taken from an ongoing group of studies designed to investigate the effects of fetal irradiation upon the subsequent behavior of the mature rat.

A previous study (Martin, 1967) tentatively established that sex differences in the activity wheel, a well established fact in intact organisms (Munn, 1950), persisted in fetally irradiated Ss. Female offspring maintained a higher activity level at both 150 and $300 \mathrm{R}$ dose levels of whole-body $\mathrm{X}$-irradiation to the gravid mothers. The $150 \mathrm{R}$ females had a higher increase in activity in the Day 19 gestation group than the 21 day group, but the reverse was true for the males. All gravid females were irradiated during the last trimester of pregnancy since a sublethal dose administered during this period results in almost no damage outside of the nervous system (Hicks, 1950).

The present study was designed to further investigate the apparent sex difference found in the 19 day group as a result of the irradiation.

Apparatus

A standard Wahmann activity wheel was connected to a Foringer counter to record revolutions.

Pregnancies

A male was placed with six to eight females of Osborne-Mendel ancestry and removed an hour later. Vaginas were checked the following morning for the presence of sperm. Three to four gravid females were randomly assigned to each treatment condition and on one of Days 17,19 , or 21 of gestation were transported to the X-ray room.

Irradiation

A Picker 280-kvp, 15-mA X-ray machine with $2.0 \mathrm{~mm} \mathrm{Al}$ inherent filter was the source. Ss were irradiated in individual Lucite boxes and the target-to-object distance was $70 \mathrm{~cm}$. Experimental Ss received $49 \mathrm{R} / \mathrm{min}$ for a total whole-body dose during the single irradiation period of $196 \mathrm{R}$. The single-shammed or control group was placed in the X-ray room on Gestation Day 19 for a comparable period of time, but the machine was not activated.

Offspring

These were weaned at 23 days of age and placed two to four to a cage according to sex and dose. Due to cannibalism or refusal to nurse by the mothers, and other factors affecting viability, not all pups reached maturity. At 60 days of age there remained five males and five females in the $17 \mathrm{day} / 200$ $R$ group, 12 males and four females in the $21 \mathrm{day} / 200 \mathrm{R}$ group, and six males and five females in the 19 day/0 $R$ group. The latter was the sole control group.

Procedure

At 60 days of age, Ss were placed in the activity wheel 15 $\mathrm{min} /$ day for five days.

\section{RESULTS}

Two Kruskal-Wallis tests (Tate \& Clelland, 1959) were run on the body weights of Ss on the first test day. This was considered necessary since irradiation usually results in smaller animals (Hicks, 1950) and conceivably this might affect activity level. Both chi squares failed to approach significance so it was assumed the weights within each sex had equalized.

An analysis of variance for unequal group size (Graybill, 1961) was performed ons the data. The statistical model assumed no interaction between Days and Sex or between Days and Irradiation. Each term was adjusted for all other terms in the model.

An $F=20.7$, df $=1 / 46, p<.01$, was obtained for Sex. The Irradiation component yielded and $F=9.13, \mathrm{df}=1 / 46$. $p<.01$. The Days component yielded an $F=7.1$, $\mathrm{df}=2 / 46$, $p=.01$, but the Irradiation by Sex interaction term failed to reach significance.

\section{DISCUSSION}

The largest portion of the variance was accounted for by sex. Experimental females remained more active than males. The 19 day $/ 200 \mathrm{R}$ males, however, werc as active as any female group.

Irradiation served to increase activity in the females in a pattern similar to the previous study in that later gestation days at treatment resulted in a smaller increase. See Fig. 1.

The scores for the males show a similar pattern to that of the females for Days 17 and 21 but with a much smaller overall increase in activity. The reason for the sharp rise on Day 19 is not inmediately apparent and is at variance with the $150 \mathrm{R}$ group in the previous study.

Hicks \& D'Amato (1961) stated that fetal irradiation has a selectively damaging effect upon the least differentiated cells in the nervous system. According to this criterion the structures most apt to be damaged would be the dorsomedial layers of the neocortex and the anterior cerebellum. It is difficult to see why there would not be a corresponding behavioral change in the comparable female group.

With the exception of the above male group none of the gestation days studied had much differential effect upon

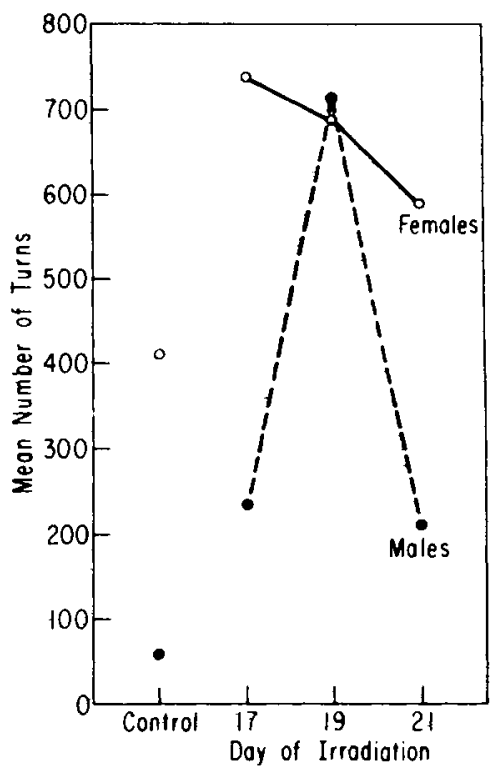

Fig. 1. Mean number of turns in the wheel as a function of sex and gestation age at irradiation. 
activity level of either sex. There is a rise in activity levels over all days with a slight return towards baseline on Day 21 . Manosevitz \& Rostkowski (1966) still found heightened activity levels in rats irradiated on the day of birth. They also found a sex difference.

The scores for the $196 \mathrm{R}$ Ss in the present study show a good fit if inserted between those of the comparable 150 and $300 \mathrm{R}$ groups of the previous experiment. The exception is the male group noted above. Interestingly enough, a 19-day group which inadvertently received a $200 \mathrm{R}$ fractionated dose, and whose data was therefore not included in the first study, also exhibited a sharp rise in activity. However, the females demonstrated an even greater rise: $\bar{x}=430$ for males, and 919 for females. Further studies are in progress to determine if this rise is a replicable phenomenon.

It can tentatively be concluded that both fetally irradiated males and females increase activity over control levels with the latter group remaining significantly more active. It also seems to be true that within the parameters of this experiment the gestation day of irradiation is a less important variable than the amount of irradiation received.

\section{REFERENCES}

GRAYBILL, F. A. An introduction to linear statistical models. New York: McGraw-Hill, 1961.

HICKS, S. P. Acute necrosis and malformations of the developing mammalian brain caused by X-ray. Proceedings of the Society of Experimental Biology \& Medicine, 1950, 75, 485-489.

MANOSEVITZ, M., \& ROSTKOWSKI, J. R. Effects of neonatal irradiation on postnatal activity and elimination. Radiation Research, $1966,28,701.707$.

MARTIN, J. C. Sex differences in the activity wheel and open field as a function of fetal X-irradiation. Psychonomic Science, 1967, 9, $415-416$.

MUNN, N. L. Handbook of psychological research on the rat. Boston: Houghton Mifflin, 1950.

TATE, M. W., \& CLELlAND, R. C. Nonparametric and shortcut statistics. Danville, Ill.: Interstate Printers \& Publishers, Inc., 1959.

\section{NOTES}

1. This research was supported by the Center for Aging and Human Development, Duke University, under NIH Grant No. 1-T1-HD-164.

2. The author wishes to thank the Department of Experimental Statistics at N. C. State University for writing the statistical program used in the main analysis.

3. Box 2921, Duke Medical Center, Durham, N. C. 27706 